\title{
VOLUMETRIC PROPERTIES OF AQUEOUS SOLUTIONS OF ALKALI HALIDES
}

\author{
by \\ TORBEN GRAVES PEDERSEN ${ }^{11}$, CHRISTIAN DETHLEFSEN ${ }^{21}$ and AASE HVIDT ${ }^{2)}$ \\ 1) Department of Chemistry, Carlsberg Laboratory, \\ Gamle Carlsberg Vej 10, DK-2500 Copenhagen Valby \\ ${ }^{21}$ Department of Chemistry, H.C. Ørsted Institute, \\ 5, Universitetsparken, DK-2100 Copenhagen Ø
}

Keywords: Electrostriction, density, ion hydration, water, excess volume

The density of aqueous solutions of $\mathrm{LiF}, \mathrm{NaF}$, or $\mathrm{KF}$, at room temperature, is measured as a function of the concentration. The measurements, together with corresponding data available on other alkali halides, are used to illustrate the concentration dependence of the apparent molar volume of the electrolytes in aqueous solution.

The data is in accordance with the conception that an essential, negative contribution to the volume is due to a progressive hydration of the ions upon dilution (i.e. with increasing water concentration).

The peculiar behaviour of the $\mathrm{Li}^{+}$-salts, compared with the other alkali halides, is associated with the small size of the $\mathrm{Li}^{+}$-ion compared with a water molecule.

\section{INTRODUCTION}

The partial volume of a component in solution can be obtained from measurements of the density of the solution as a function of the concentration. In this way density measurements are used as a tool in attempts to elucidate pressure effects on chemical equilibria or reaction rates $(1,13,14,17)$, or to explain the sedimentation of macromolecular systems by ultracentrifugation $(16,19)$. More generally, the density of liquid systems may contribute information about the weak molecular interactions in the liquid state. Although the detailed interpretation is far from accomplished, some insight into liquid systems at the molecular level - in particular the behaviour of water as a solvent - is gained from density measurements $(7,9,10,14$, 17). Whereas the volume change on mixing two nonpolar liquids is usually less than 1 to 2 $\mathrm{cm}^{3} \mathrm{~mole}^{-1}$ (13), volume effects exhibited in aqueous systems can be considerably larger. The ionization volume of water $\left(-22.3 \mathrm{~cm}^{3} \mathrm{~mole}^{-1}(14\right.$, $15)$ ), as well as the negative partial volume of f.ex. $\mathrm{MgSO}_{4}$ in dilute aqueous solution (8), indicate that at least part of the volume effects observed in aqueous solutions of electrolytes must be due to interactions of the ions with solvent water, i.e. to solvation effects known as electrostriction of water (5).

In the literature most volumetric investigations of aqueous solutions focus interest on estimates of the volume of the solute at infinite dilution. It is the aim of the present paper, in addition, to illustrate the concentration dependence of the volume of aqueous solutions of alkali halides over the entire solubility range. Comprehensive data on the density of solutions, at room temperature, of most of the alkali halides is available in the literature, although information about the fluorides is limited. By means of an 
automatic densimeter equipment we have measured the density of aqueous solutions of LiF, $\mathrm{NaF}$, or $\mathrm{KF}$ as a function of the concentration. These measurements, together with available data on alkali halide solutions, are presented as plots of the apparent molar volume of the salts versus the mole fraction. The mole fraction concentration scale is chosen in order to draw immediate attention to the concentration of both components in the solutions, an alkali halide and water. In the discussion of the experimental data the non-ideal volumetric behaviour of the solutions is associated with solute-solvent interactions, considered as hydration of the ions.

\section{MATERIALS}

$\mathrm{LiF}, \mathrm{NaF}$, and $\mathrm{KF}$ are analytical grade from $\mathrm{E}$. Merck, Darmstadt. The salts are dried at $200^{\circ} \mathrm{C}$ for 48 hours, and used without any further purification.

Water used is glass distilled.

\section{EXPERIMENTAL}

Densities are measured by means of a vibrating-tube densimeter cell (Anton Paar, Model DMA 02) (20), calibrated with air and with pure water. The density of water at $25^{\circ} \mathrm{C}$ is 0.997048 $\mathrm{gcm}^{.3}$ (12). The cell is built into a computer controlled set-up for automatic measurements of the density of solutions as a function of the concentration. Details of the equipment are described elsewhere (4).

Starting solutions of the salts are prepared by weighing, and automatically diluted by stepwise additons of pure water. The equipment makes it possible, with a moderate effort, to obtain a number of density measurements - appropriately distributed over a given concentration range - sufficient for a numerical fitting of a model with 4 - 5 adjustable parameters (4).

\section{THEORETICAL}

The apparent molar volume of a solute, at the mole fraction $x_{1}$, is defined as

$$
V_{1}^{a p p}=\left(V_{m}-x_{0} V_{o}^{*}\right) / x_{1}
$$

$V_{m}$ is the molar volume of the solution. The subscripts 1 and $o$ refer to the solute (an alkali halide) and to water, respectively, $\left(x_{1}+x_{0}=1\right)$. The superscript * indicates the pure, liquid state at the temperature of the experiments. $V_{1}{ }^{\text {app }}$ represents the volume increment per mole of solute added to a known amount of solvent.

Eq. (1) is in accordance with the following formulation of $V_{l}^{\text {app }}$ in terms of the directly measured densities, $d$, and weight fractions, $w$,

$$
V_{1}^{\text {app }}=M_{1}\left[1 / d_{0}^{*}+\left(1 / d-1 / d_{o}^{*}\right) / w_{1}\right]
$$

In attempts to interpret volumetric data it may be useful to consider the following formulation of $V_{1}^{\text {app }}$

$$
V_{1}^{\text {app }}=V_{1}^{*}+V_{m}^{E} / x_{1}
$$

where $V_{m}^{E}$ is the molar excess volume of the solution

$$
\mathrm{V}_{\mathrm{m}}^{\mathrm{E}}=\mathrm{V}_{\mathrm{m}}-\left(\mathrm{x}_{1} \mathrm{~V}_{\mathrm{i}}^{*}+\mathrm{x}_{\mathrm{o}} \mathrm{V}_{\mathrm{o}}^{*}\right)
$$

In eq. (3) the apparent molar volume of the solute is considered as a sum of the molar volume $\left(\mathrm{V}_{i}^{*}\right)$ of the pure solute in a (hypothetical) liquid state, i.e. for $x_{1}=1$, and $V_{m}^{E} / x_{1}$ which is the excess volume of the solution per mole of the solute.

We have tentatively estimated $\mathrm{V}_{1}^{*}$ of alkali halides at room temperature by extrapolating volumetric data on the molten salts (11), assuming a constant expansivity coefficient, $\alpha$, over the entire temperature range, viz.

$$
\mathrm{V}_{1}^{*}(298 \mathrm{~K})=\mathrm{V}_{1}^{*}(\mathrm{~T})[1+\alpha(298-\mathrm{T})]
$$

Table I summarizes the calculated values of $V_{1}^{*}$, together with the molar volume of the salts in the crystalline state $\left(V_{1}^{c r}\right)$, and the "intrinsic" volume, defined as

$$
V_{1}^{\text {intr }}=4 \pi / 3\left(R^{3}+R^{3}\right) L
$$

In eq. (5) $R$ denotes the ionic radii ((2)p.61), and $L$ is Avogadro's number. Estimated values of the intrinsic volume of water vary from 6.5 to 12.4 $\mathrm{cm}^{3} \mathrm{~mol}^{-1}((2)$ p. 534, (6), (21)).

The volume of a liquid is a sum of the intrinsic volume of the molecular and/or ionic species present, and the empty space between them. On the assumption that the intrinsic volume remains constant, the excess volume of a liquid mixture is the difference between the empty space in the mixture and in the pure components. Thus the excess volume is a measure of a difference in the packing of the species present in the two states.

Serious problems are burdening attempts to interpret volumetric data on aqueous solutions of electrolytes. Difficulties involved in achieving 
Table I.

Calculated molar volumes, in $\mathrm{cm}^{3} \mathrm{~mol}^{-1}$, of alkali halides at $25^{\circ} \mathrm{C}$.

The ionic radii, in A, (ref. (2), p.61) are given in parenthesis.

\begin{tabular}{|c|c|}
\hline $\begin{array}{l}v_{1}^{\text {intr }} \\
v_{1}^{c r} \\
\end{array}$ & $\begin{array}{l}\text { intrinsic volume (eq. (5)) } \\
\text { crystal volume (ref. (24)) } \\
\text { liquid volume (eq. (4)) }\end{array}$ \\
\hline
\end{tabular}

\begin{tabular}{|c|c|c|c|c|}
\hline & $F^{-}(1.33)$ & $\mathrm{Cl}^{-}(1.81)$ & $\mathrm{Br}^{-}(1.96)$ & $I^{-}(2.19)$ \\
\hline $\mathrm{Li}^{+}(0.68)$ & $\begin{array}{l}6.73 \\
\quad 9.96 \\
\quad 11.61\end{array}$ & $\begin{array}{l}15.77 \\
20.43 \\
24.10\end{array}$ & $\begin{array}{l}19.82 \\
25.12 \\
30.26\end{array}$ & $\begin{array}{l}27.28 \\
\quad 32.95 \\
38.07\end{array}$ \\
\hline $\mathrm{Na}^{+}(0.98)$ & $\begin{array}{l}8.32 \\
\quad 15.05 \\
\quad 16.38\end{array}$ & $\begin{array}{l}17.36 \\
26.96 \\
29.58\end{array}$ & $\begin{array}{l}21.38 \\
\quad 32.16 \\
\quad 35.10\end{array}$ & $\begin{array}{l}28.89 \\
\quad 40.84 \\
44.82\end{array}$ \\
\hline $\mathrm{K}^{+} \quad(1.33)$ & $\begin{array}{r}11.88 \\
23.43 \\
23.69\end{array}$ & $\begin{array}{l}20.94 \\
\quad 37.68 \\
38.02\end{array}$ & $\begin{array}{l}24.93 \\
43.27 \\
43.87\end{array}$ & $\begin{array}{l}32.46 \\
\quad 53.04 \\
\quad 53.99\end{array}$ \\
\hline $\mathrm{Rb}^{+}(9.48)$ & $\begin{array}{r}14.12 \\
29.35 \\
\end{array}$ & $\begin{array}{l}23.14 \\
43.80 \\
42.30\end{array}$ & $\begin{array}{l}26.88 \\
49.37 \\
48.37\end{array}$ & $\begin{array}{l}34.69 \\
\quad 59.83 \\
58.85\end{array}$ \\
\hline $\mathrm{Cs}^{+}(1.67)$ & $\begin{array}{l}17.70 \\
36.91 \\
\quad 33.63\end{array}$ & $\begin{array}{l}26.76 \\
\quad 42.42 \\
48.79\end{array}$ & $\begin{array}{l}30.75 \\
\quad 47.93 \\
54.84\end{array}$ & $\begin{array}{l}38.25 \\
\quad 57.61 \\
\quad 66.82\end{array}$ \\
\hline
\end{tabular}

a reasonable estimate of $V_{1}^{*}$ (in eq. (3)) of a salt makes the calculated value of the excess volume of a solution somewhat uncertain. Another problem is related to the fact that the intrinsic volume of a water molecule, and of some of the ions considered, is comparable to the free space in the liquids. The particles of one component can enter in part into interstices of the other component, and in this way give rise to negative contributions to the excess volume, which are independent of the electric charge, and difficult to evaluate $(2,10)$.

It is well known that structural changes of water may give rise to rather unique volume effects, and volumetric investigations are therefore, in spite of the above mentioned reservations, considered to be useful as a tool to elucidate interactions of water with solute species $(1$, $2,10,13,17)$. Structural changes of water do not explicitly enter treatments of electrolyte solutions along the lines of the DEBYE-HÜCKEL theory ((2) p. 409); the charged species considered are defined as "hydrated ions", and only interactions between such species are involved. In the present paper we focus on the hydration of the ions, which is considered as solute-solvent equilibria (23). Such equilibria are displaced with changes in the concentration, and the 
T. G. Pedersen et al.: Volume of alkali halide solutions

Table I I.

Density, d, of aqueous solutions of $\mathrm{LiF}, \mathrm{NaF}$ and $\mathrm{KF}$ at $25^{\circ} \mathrm{C}$. a stands for $10^{4} \mathrm{w}_{1}$ (for $\mathrm{LiF}$ ) and $10^{3} \mathrm{w}_{1}$ (for $\mathrm{NaF}$ and $\mathrm{KF}$ ), where $\mathrm{w}_{1}$ is the weight fraction of the alkali halide. $b$ stands for $\left(d-d_{0}^{*}\right) 10^{3} / \mathrm{gcm}^{-3} \cdot d_{0}^{*}=0.997048 \mathrm{gcm}^{-3}(12)$.

a

b

$\mathrm{b}$

a

$\mathrm{b}$

LiF

$\begin{array}{llll}3.77 & 0.407 & 5.29 & 0.565 \\ 3.82 & 0.411 & 5.32 & 0.571 \\ 4.07 & 0.438 & 5.59 & 0.596 \\ 4.12 & 0.444 & 5.62 & 0.601 \\ 4.38 & 0.471 & 5.89 & 0.628 \\ 4.42 & 0.477 & 5.92 & 0.633 \\ 4.68 & 0.503 & 6.20 & 0.661 \\ 4.72 & 0.508 & 6.22 & 0.666 \\ 4.98 & 0.535 & 6.50 & 0.694 \\ 5.02 & 0.539 & 6.53 & 0.698\end{array}$

$\mathrm{NaF}$

\begin{tabular}{|c|c|c|c|}
\hline 0.594 & 0.627 & 2.255 & 2.37 \\
\hline 0.632 & 0.670 & 2. 329 & 2.4 \\
\hline 0.670 & 0.705 & 2.389 & 2.5 \\
\hline 0.707 & 0.746 & 2.406 & 2.5 \\
\hline 0.745 & 0.790 & 2.480 & 2.6 \\
\hline 0.783 & 0.826 & 2.540 & 2.6 \\
\hline 0.820 & 0.867 & 2.691 & 2.8 \\
\hline 0.858 & 0.906 & 2.841 & 2.9 \\
\hline 0.895 & 0.944 & 2.992 & 3.1 \\
\hline 0.933 & 0.984 & 3.143 & 3.2 \\
\hline 0.971 & 1.022 & 3.293 & 3.4 \\
\hline 1.008 & 1.066 & 3.443 & 3.6 \\
\hline 1.046 & 1.105 & 3.539 & 3.7 \\
\hline $1.083^{\circ}$ & 1.143 & 3.594 & 3.7 \\
\hline 1.121 & 1.183 & 3.744 & 3.9 \\
\hline 1.122 & 1.184 & 3.796 & 3.98 \\
\hline 1.158 & 1.221 & 3.895 & 4.08 \\
\hline 1.196 & 1.258 & 4.046 & 4.2 \\
\hline 1.197 & 1.266 & 4.052 & 4.2 \\
\hline 1.234 & 1.301 & 4.196 & 4.39 \\
\hline 1.273 & 1.346 & 4.308 & 4.51 \\
\hline 1.349 & 1.425 & 4.345 & 4.55 \\
\hline 1.424 & 1.502 & 4.497 & 4.71 \\
\hline 1.500 & 1.581 & 4.563 & 4.7 \\
\hline 1.575 & 1.663 & 4.546 & 4.8 \\
\hline 1.651 & 1.741 & 4.798 & 5.0 \\
\hline 1.726 & 1.818 & 4.821 & 5.0 \\
\hline
\end{tabular}

$\begin{array}{llll}6.80 & 0.729 & 8.32 & 0.886 \\ 6.83 & 0.730 & 8.33 & 0.887 \\ 7.10 & 0.759 & 8.62 & 0.917 \\ 7.13 & 0.761 & 8.63 & 0.918 \\ 7.41 & 0.791 & 8.92 & 0.950 \\ 7.43 & 0.793 & 8.93 & 0.951 \\ 7.71 & 0.823 & 9.22 & 0.982 \\ 7.73 & 0.824 & 9.23 & 0.982 \\ 8.01 & 0.854 & 9.52 & 1.013 \\ 8.03 & 0.855 & 9.53 & 1.014\end{array}$

$\begin{array}{llll}6.609 & 6.910 & 16.769 & 17.485\end{array}$

$\begin{array}{llll}6.865 & 7.178 & 16.951 & 17.678\end{array}$

$7.068 \quad 7.401$

$17.643 \quad 18.393$

$18.104 \quad 18.879$

$18.521 \quad 19.306$

$19.252 \quad 20.069$

$19.396 \quad 20.211$

$20.264 \quad 21.108$

$20.402 \quad 21.263$

$21.141 \quad 22.021$

$21.546 \quad 22.449$

$22.010 \quad 22.918$

$22.696 \quad 23.641$

$22.879 \quad 23.825$

$23.749 \quad 24.724$

$23.838 \quad 24.823$

$24.624 \quad 25.626$

$24.977 \quad 26.010$

$25.483 \quad 26.521$

$26.116 \quad 27.189$

$26.356 \quad 27.424$

$27.224 \quad 28.326$

$27.258 \quad 28.372$

$28.081 \quad 29.213$

$28.401 \quad 29.557$

$28.949 \quad 30.095$

$29.535 \quad 30.731$ 
T. G. Pedersen et al.: Volume of alkali halide solutions

a

$\begin{array}{llll}1.802 & 1.899 & 4.947 & 5.168 \\ 1.877 & 1.974 & 5.076 & 5.319 \\ 1.952 & 2.059 & 5.331 & 5.581 \\ 2.028 & 2.137 & 5.587 & 5.850 \\ 2.088 & 2.198 & 5.842 & 6.116 \\ 2.103 & 2.215 & 6.099 & 6.379 \\ 2.178 & 2.294 & 6.353 & 6.646 \\ 2.238 & 2.350 & & \end{array}$

KF

\begin{tabular}{|c|c|c|c|c|c|c|c|}
\hline 3.012 & 2.611 & 28.622 & 24.508 & 71.669 & 62.270 & 134.070 & 119.095 \\
\hline 3.385 & 2.929 & 30.057 & 25.736 & 71.921 & 62.596 & 135.925 & 120.616 \\
\hline 3.756 & 3.248 & 31.499 & 26.974 & 72.194 & 62.796 & 139.412 & 124.066 \\
\hline 4.127 & 3.568 & 32.929 & 28.200 & 74.016 & 64.340 & 140.271 & 124.660 \\
\hline 4.498 & 3.887 & 33.176 & 28.617 & 75.079 & 65.398 & 144.532 & 128.640 \\
\hline 4.870 & 4.204 & 34.349 & 29.422 & 76.326 & 66.382 & 144.679 & 128.975 \\
\hline 5.241 & 4.524 & 35.784 & 30.653 & 76.943 & 67.014 & 148.822 & 132.623 \\
\hline 5.611 & 4.839 & 37.204 & 31.876 & 78.238 & 68.200 & 149.943 & 133.913 \\
\hline 5.983 & 5.162 & 38.109 & 32.895 & 78.660 & 68.453 & 155.157 & 138.806 \\
\hline 6.351 & 5.476 & 38.625 & 33.101 & 81.391 & 71.014 & 160.269 & 143.625 \\
\hline 6.573 & 5.661 & 40.034 & 34.313 & 81.667 & 71.220 & 165.392 & 148.489 \\
\hline 6.721 & 5.792 & 40.554 & 35.005 & 84.504 & 73.781 & 170.494 & 153.320 \\
\hline 6.790 & 5.803 & 41.454 & 35.544 & 86.366 & 75.437 & 175.540 & 158.124 \\
\hline 7.092 & 6.108 & 42.856 & 36.756 & 87.633 & 76.576 & 177.745 & 160.105 \\
\hline 7.312 & 6.292 & 42.997 & 37.134 & 90.720 & 79.347 & 180.490 & 162.873 \\
\hline 7.814 & 6.693 & 44.269 & 37.978 & 91.015 & 79.591 & 185.445 & 167.614 \\
\hline 8.051 & 6.934 & 45.661 & 39.179 & 93.808 & 82.114 & 187.499 & 169.356 \\
\hline 8.834 & 7.553 & 47.071 & 40.390 & 95.635 & 83.767 & 190.381 & 172.351 \\
\hline 9.528 & 8.200 & 47.869 & 41.368 & 96.872 & 84.865 & 195.273 & 176.968 \\
\hline 10.263 & 8.829 & 49.326 & 42.706 & 99.930 & 87.613 & 197.091 & 178.716 \\
\hline 10.883 & 3.287 & 50.290 & 43.480 & 100.246 & 87.932 & 206.563 & 188.023 \\
\hline 11.000 & 9.420 & 52.605 & 45.575 & 101.179 & 88.939 & 215.829 & 197.181 \\
\hline 11.733 & 10.094 & 52.688 & 45.578 & 102.960 & 90.336 & 225.020 & 206.250 \\
\hline 11.939 & ro. 179 & 55.101 & 47.600 & 104.814 & 92.075 & 234.061 & 215.353 \\
\hline 12.470 & 10.637 & 55.854 & 48.422 & 105.988 & 93.055 & 242.941 & 224.347 \\
\hline 13.094 & 11.157 & 57.478 & 49.767 & 106.778 & 94.026 & 251.731 & 233.324 \\
\hline 13.204 & 11.259 & 59.094 & 51.271 & $108.99 t$ & 95.694 & 260.407 & 242.239 \\
\hline 13.934 & 11.986 & 59.877 & 51.879 & 109.346 & 96.193 & 268.878 & 251.014 \\
\hline 14.125 & 11.989 & 62.250 & 53.964 & 112.328 & 99.086 & 277.282 & 259.775 \\
\hline 14.667 & 12.503 & 62.333 & 54.122 & 113.871 & 100.309 & 285.551 & 268.445 \\
\hline 16.192 & 13.791 & 62.570 & 54.244 & 117.826 & 104.115 & 293.793 & 277.176 \\
\hline 19.942 & 17.091 & 64.623 & 55.969 & 118.336 & 104.400 & 301.769 & 285.646 \\
\hline 21.399 & 18.332 & 65.542 & 56.952 & 122.788 & 108.475 & 309.793 & 294.245 \\
\hline 22.850 & 19.569 & 66.973 & 58.114 & 123.294 & 109.139 & 317.628 & 302.722 \\
\hline 24.294 & 20.807 & 67.392 & 58.530 & 127.182 & 112.519 & 325.322 & 311.080 \\
\hline 25.740 & 22.038 & 68.735 & 59.776 & 128.711 & 114.139 & 332.939 & 319.395 \\
\hline 27.187 & 23.278 & 69.338 & 60.207 & 131.593 & 116.593 & 340.440 & 327.486 \\
\hline
\end{tabular}

$\begin{array}{llll}15.013 & 15.667 & 30.669 & 31.907 \\ 15.200 & 15.833 & 31.795 & 33.068 \\ 15.702 & 16.347 & 32.929 & 34.239 \\ 15.798 & 16.481 & 34.066 & 35.418 \\ 15.891 & 16.573 & 35.196 & 36.588 \\ 16.213 & 16.877 & 36.311 & 37.744 \\ 16.715 & 17.389 & 37.440 & 38.894\end{array}$


T. G. Pedersen et al.: Volume of alkali halide solutions
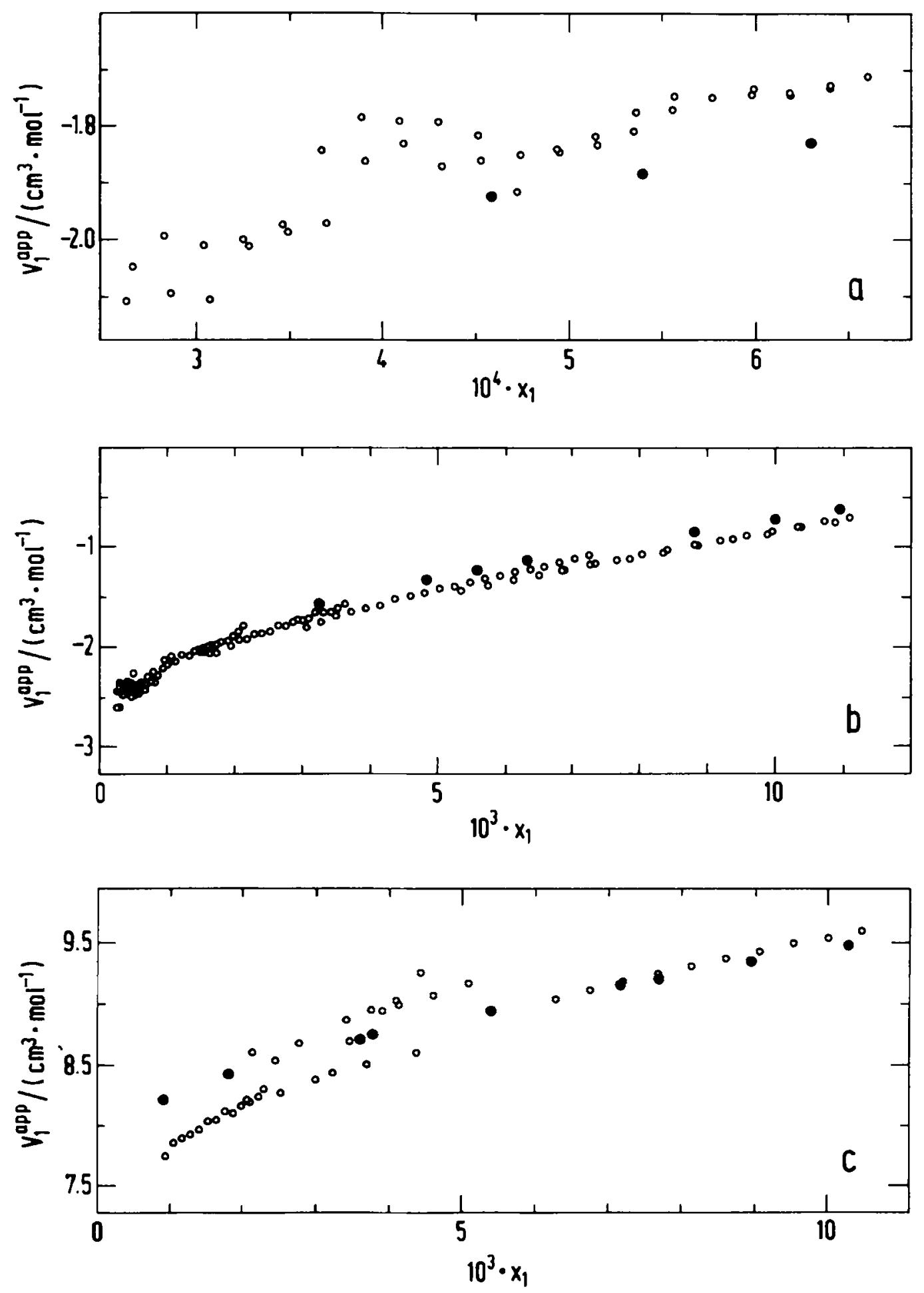

Figure 1. The apparent molar volume, $\mathrm{V}_{1}^{\text {ppp }}$, of $\mathrm{a}: \mathrm{LiF}, \mathrm{b}: \mathrm{NaF}$, and $\mathrm{c}$ : $\mathrm{KF}$ in aqueous solution at $25^{\circ} \mathrm{C}$. $\mathrm{V}_{1}^{\text {app }}$ is calculated according to eq. (2) for values of the density reported in Table $11(O)$, and in Ref. (3) (๑). $x_{1}$ is the mole fraction of the salts. 
accompanying volume changes are suggested to be the main source of the non-ideal concentration dependence observed of the volume of aqueous electrolyte solutions.

\section{RESULTS}

The density of aqueous solutions, at room temperature, of $\mathrm{LiF}, \mathrm{NaF}$, or $\mathrm{KF}$ is measured over the entire solubility range. The experimental results are reported in Table II. Measurements on the most dilute solutions are illustrated in Figure 1 by plots of $V_{1}^{\text {app }}$ (calculated according to eq. (2)) vs. the mole fraction. This figure includes data available in the literature (3). It may be noted that the apparent molar volume of $\mathrm{LiF}$ and $\mathrm{NaF}$ in aqueous solution is negative.

Measurements, made by our equipment, of the density of $\mathrm{NaCl}$ solutions are in agreement with corresponding data in International Critical Tables (8). They support the conclusion reached previously $(22)$ that the data in reference (8) are comparable with data obtained by vibration tube densimeters.

\section{DISCUSSION}

The apparent molar volume, $\mathrm{V}_{1}^{\text {app }}$, of alkali chlorides, bromides, and iodides in aqueous solution at room temperature, calculated from available experimental data (8), is presented in Figure 2 as a function of the mole fraction. It is seen from this figure, and from the fluoride volumes in Figure 1, that apart from the $\mathrm{Li}^{+}$salts, $V_{1}^{\text {app }}$ of the salts is larger the larger the ions involved (see Table I), and increases with increasing concentration.

The peculiar behaviour of the $\mathrm{Li}^{+}$-salts is more obvious from the plots in Figure 3, which represents the function $V_{1}^{\text {app }}-V_{1}^{*}$ i.e. (according to eq. (3)) the excess volume of the solutions per mole of the salt $\left(V_{m}^{E} / x_{1}\right)$. It appears from this figure that the excess volume of the solutions is in all cases negative, and - with the exception of the $\mathrm{Li}^{+}$-salts - numerically larger the smaller the ions.

It was discussed, already in 1894 by DRUDE and NERNST (5), that the dissociation of electrolytes in aqueous solution gives rise to negative volume changes. Considering two oppositely charged, monovalent ions as spheres, immersed in a uniform dielectric medium with the dielectric constant $\varepsilon$, the electrostatic contribution to the Gibbs free energy may be expressed as

$$
\mathrm{G}_{\mathrm{el}}=-\mathrm{e}^{2} / \varepsilon r
$$

where $e$ is the elementary charge, and $r$ is the interionic distance. The corresponding contribution to $V_{1}^{\text {app }}$ is

$$
V_{e l}=\left(\partial G_{e l} / \partial P\right)_{r}=-G_{e l}(\partial \ln \varepsilon / \partial P) \text {. }
$$
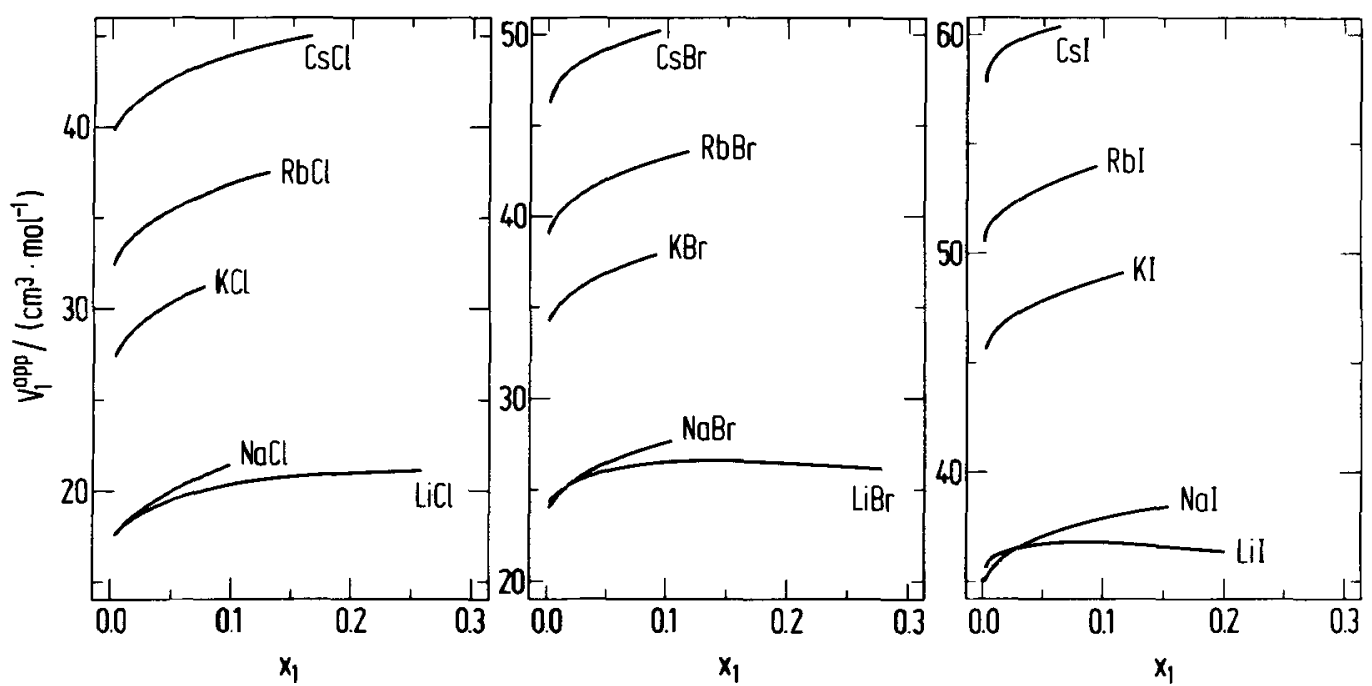

Figure 2. The apparent molar volume, $V_{1}^{\text {app }}$, calculated according to eq. (2) for values of the density reported in Ref. (8). $x_{1}$ is the mole fraction of the salts. 
T. G. PeDersen et al.: Volume of alkali halide solutions

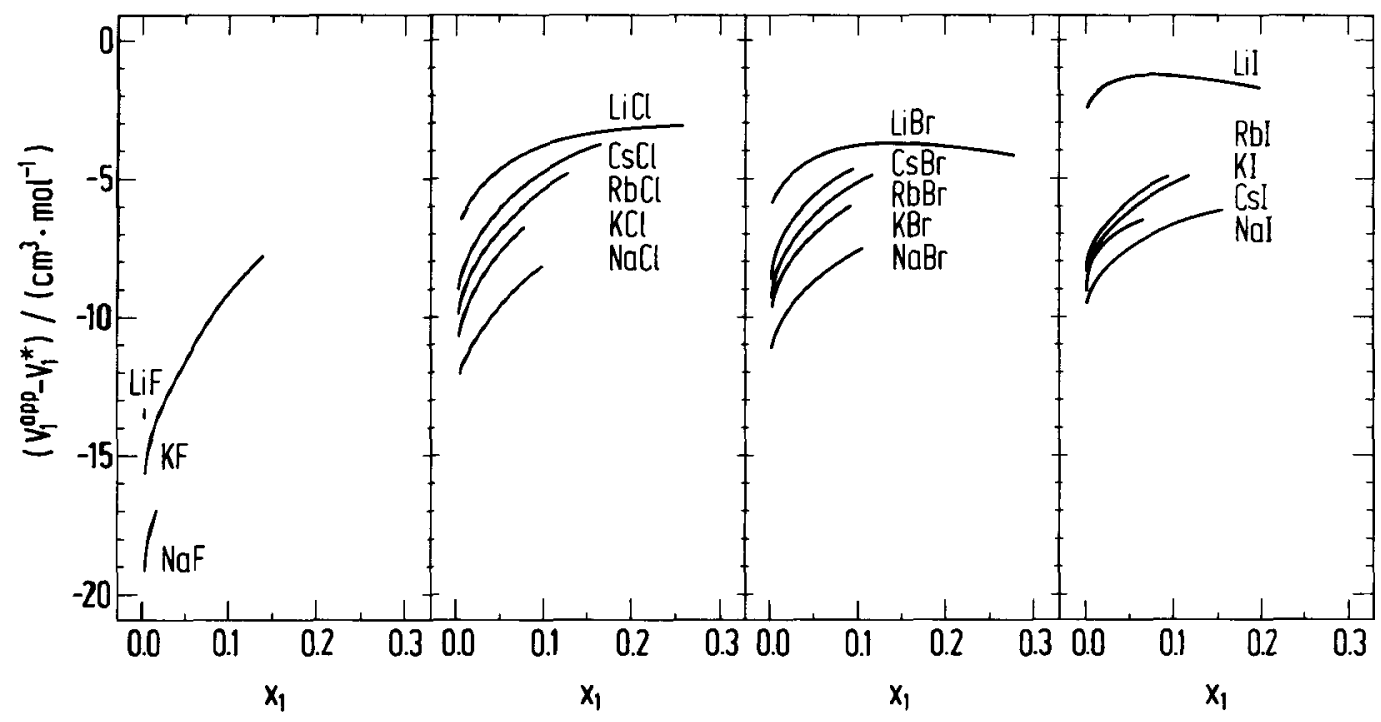

Figure 3. The excess volume of aqueous alkali halide solutions at $25^{\circ} \mathrm{C}$, calculated per mole of the solute, $V_{1}^{a p p}-V_{1}^{*}=V_{m}^{\varepsilon} / x_{1}$ (see eq. (3)). $x_{1}$ is the mole fraction of the salts. Experimental data as in Fig. 1 and 2.

Figure 4 shows plots of the electrostatic contribution to the free energy and the volume of dilute electrolyte solutions, calculated according to eq. (6) and (7), for $\varepsilon=78.3$, and $\partial \ln \varepsilon / \partial P=$ $47.10 \times 10^{-6}$ bar $^{-1}(18)$. The smallest distance between two ions is the sum of the ionic radii, so according to this model the volume change of dissociation is $-V_{e l}\left(R_{+}+R\right)$.

This simple model of electrostatic interaction, based on the assumption that the solvent is uniform, is unable to account for the concentration dependence of the apparent molar volume of alkali halides, seen in Figure 1 and 2. In particular, the model does not explain the negative values of $V_{1}^{\text {app }}$ observed for $\mathrm{LiF}$ and $\mathrm{NaF}\left(\mathrm{V}_{1}^{\text {intr }}\right.$ $-V_{\mathrm{el}}\left(R_{+}+R_{-}\right)>0$, see Table I and Figure 4). A more likely explanation of the experimental data is the existence of local structural changes of water around the ions, i.e. of ion hydration $(2,9$, 23).

In discussions of the hydration of ions it is sometimes assumed that an ion, dissolved in water, is and remains surrounded by a sphere of a certain number of water molecules, bound to the ion. Apart from the objection, that it is not possible to state unambiguously what is meant by a water molecule being "bound to an ion", hydration sphere models - with a constant num-

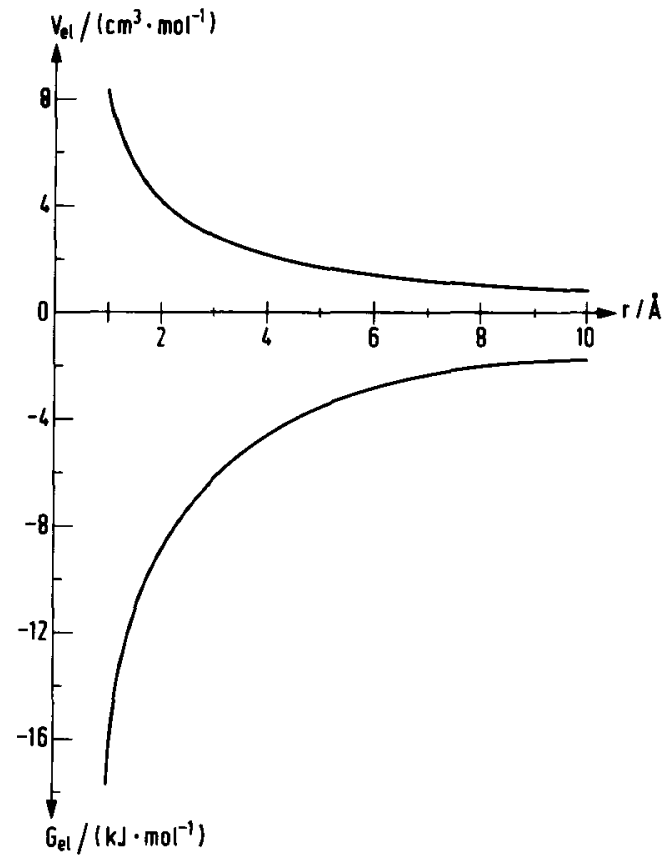

Figure 4. The electrostatic contribution to the molar volume, $V_{\mathrm{el}}$, and the molar Gibbs free energy, $G_{\mathrm{el}}$, of an electrolyte, calculated according to eq. (6) and (7). $r$ is the distance between the two monovalent ions. 

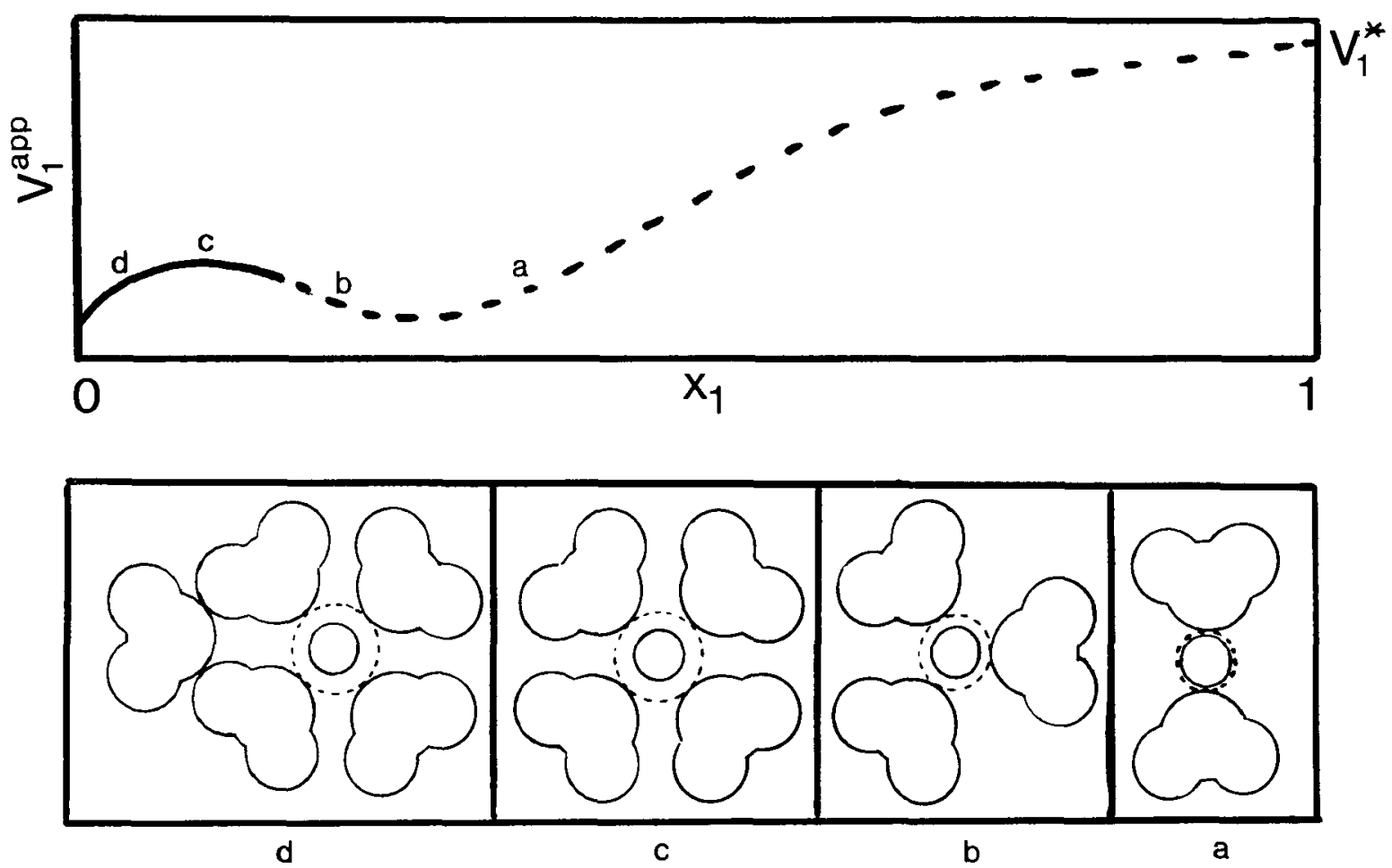

Figure 5. Outline of the course of the hydration of a $\mathrm{Li}^{+}$-ion. $\mathrm{x}_{1}$ is the mole fraction of a Li-salt.

ber of water molecules bound per ion - can hardly explain the concentration dependence of the volume, illustrated in Figures $1-3$. There is no tendency of a levelling off of the apparent molar volume of the alkali halides, when the concentration approaches zero. On the contrary, the steepness $\left(\partial V_{1}^{a p p} / \partial x_{1}\right)$ of the curves increases for $\mathrm{x}_{1} \rightarrow 0$.

The volumetric data is, however, in accordance with the equilibrium model of ionic hydration, proposed by STOKES and ROBINSON (23). In this model the hydration of an electrolyte is formally treated as a series of consecutive equilibria between the cation, $\mathrm{C}^{+}$, and water: $\mathrm{C}^{+}\left(\mathrm{H}_{2} \mathrm{O}\right)_{i-1}$ $+\mathrm{H}_{2} \mathrm{O} \rightleftarrows \mathrm{C}^{+}\left(\mathrm{H}_{2} \mathrm{O}\right)_{\mathrm{i}}$, of which $\mathrm{K}_{\mathrm{i}+1} / \mathrm{K}_{\mathrm{i}}<1$, where $\mathrm{K}_{\mathrm{i}}$ is the equilibrium constant of the i'th reaction. The model is shown to give good quantitative account of the osmotic coefficient of electrolytes up to high concentrations (23). In the development of this model, volume changes due to the hydration are ignored, but a consideration of the concentration dependence of the volume of alkali halide solutions may actually support the model. The decrease of the apparent molar volume of the electrolytes, when the concentration approaches zero, is in accordance with displacement towards the right-hand side of hydration equilibria $\mathrm{C}^{+}\left(\mathrm{H}_{2} \mathrm{O}\right)_{\mathrm{i}-1}+\mathrm{H}_{2} \mathrm{O} \rightleftarrows \mathrm{C}^{+}\left(\mathrm{H}_{2} \mathrm{O}\right)_{i}$ and $\mathrm{A}^{\prime}\left(\mathrm{H}_{2} \mathrm{O}\right)_{j-1}+\mathrm{H}_{2} \mathrm{O} \rightleftarrows \mathrm{A}\left(\mathrm{H}_{2} \mathrm{O}\right)_{j}$ of which the volume change $\Delta \mathrm{V}^{\theta}<0$.

The remarkable behaviour of the $\mathrm{Li}^{+}$-salts - the relatively small electrostriction of water and the maximum of the apparent molar volume of $\mathrm{LiBr}$ and LiI as a function of the concentration (see Figure (2)) - may be associated with the small size of the $\mathrm{Li}^{+}$-ion, compared with a water molecule. The volume change of the binding of the first and the second water molecule to $\mathrm{Li}^{+}$-ion is supposedly negative, due to electrostatic interactions between the ion and the dipolar water molecules (Figure 5a). However, three or four water molecules, attached to a $\mathrm{Li}^{+}$-ion, may require some extra space, due to the mutual repulsion of the dipolar water molecules, oriented by the ion (Figure $5 \mathrm{~b}-\mathrm{c}$ ). The further addition of water molecules to the hydration 
sphere appears to be accompanied by the "normal" volume decrease (Figure 5d). This hypothetical course of the hydration of a $\mathrm{Li}^{+}$-ion, and of $V_{1}^{\text {app }}$ of a Li-salt is outlined in Figure 5. Unfortunately, the dotted part of the curve, representing $V_{1}^{\text {app }}$, eludes experimental verification, due to the low solubility of the Li-salts. The value of $V_{1}^{*}$ of Li-salts (Table I), i.e. of $V_{1}^{a p p}(x=1)$ indicates that a minimum of $V_{1}^{\text {app }}$ must occur at a concentration beyond the experimentally accessible range.

It is an essential feature of the hydration equilibrium model, that the standard Gibbs free energy for the attachment of a water molecule to an ion changes by an amount $-\mathrm{RT} \ln \mathrm{K}_{\mathrm{i}}$ for each successive step of the hydration (23). For most of the electrolytes considered this free energy change is estimated to be negative for the attachment of the first water molecules, but positive for the attachment of the fifth (or higher) water molecules (23). This means that labile hydration equilibria exist in dilute aqueous electrolyte solutions, and they apparently give rise to measurable volume changes. Similar volume effects observed in aqueous solutions of non-electrolytes have been associated with the unique ability of water to undergo structural changes (introduced by solute species), characterized by relatively small changes in Gibbs free energy, but remarkably large changes in volume and enthalpy $(4,10)$. Such solute-solvent interactions are decisive for the thermodynamic properties of aqueous solutions, and they may explain the pronounced deviations from ideality which are typical of even very dilute aqueous solutions.

\section{ACKNOWLEDGEMENTS}

We wish to thank Professor Martin OTTESEN for his stimulating interest in this work, and for his critical review of the manuscript. Mrs. GERDA NIELSEN is thanked for excellent technical assistance.

\section{REFERENCES}

1. ASANO. T. \& W.J. LE NOBLE: Activation and reaction volumes in solution. Chem. Rev. 78, 407-489 (1978)

2. CONWAY, B.E.: Ionic hydration in chemistry and biophysics. Elsevier, Amsterdam (1981)
3. Desnoyers, J.E., M. Arel, G. Perron \& C. JoliCOEUR: Apparent molal volumes of alkali halides in water at $25^{\circ} \mathrm{C}$. Influence of structural hydration interactions on the concentration dependence. J. Phys. Chem. 73, 3346-3351 (1969)

4. Dethlefsen, C., P.G. Sørensen \& Aa. Hvidt: Excess volumes of propan-1-ol and water at $278.15,288.15$ and $298.15 \mathrm{~K}$. J. Solution Chem. 191-210(1984)

5. DRude, P. \& W. NeRnST: Über Elektrostriktion durch freie Ionen. Zeitschrift für physikalische Chemie 15, 79-85 (1894)

6. EDWARD. J.T.: Molecular volumes and the StokesEinstein equation. J. Chem. Educ. 47, 261-270 (1970)

7. FRank, H.S. \& M.W. Evans: Free volume and entropy in condensed systems. J. Chem. Phys. 13, 507-532 (1945)

8. GiLLESPIE, L.J.: Density (specific gravity) and thermal expansion (under atmospheric pressure) of aqueous solutions of inorganic substances and of strong elektrolytes. In: E.W.Washburn, ed., International Critical Tables of Numerical Data, Physics, Chemistry and Technology, McGraw-Hill, New York, Vol. 3, pp. 77-95 (1928)

9. GURNEY, R.W.: Ionic processes in solution, chapter 11. McGraw-Hill Book Company, Inc. (1953)

10. HVIDT. AA.: Interactions of water with nonpolar solutes. Ann. Rev. Biophys. Bioeng. 12, 1-20 (1983)

11. JANZ, G.J.: Molten Salts Handbook. Academic Press, New-York-London (1967)

12. KELL,G.S.: Effects of isotopic composition, temperature, and dissolved gases on the density of liquid water. J. Phys. Chem. ref. Data 6, 1109-1131 (1977)

13. Kelm, H. \& D.A. Palmer: Determination of volumes of activation. In: H.Kelm, ed., High Pressure Chemistry. D. Reidel Publishing Company, Holland, U.S.A., England. pp. $281-309$ (1978)

14. LE NOBLE, W.J.: Organic model reactions under pressure. In: H.Kelm, ed., High Pressure Chemistry, D. Reidel Publishing Company, Holland, U.S.A., England. pp. 325-363 (1978)

15. LinderstrøM-LANG. K. \& C.F. JACOBSEN: The contraction accompanying enzymatic breakdown of proteins. Compt. Rend. Trav. Lab. Carlsberg, Ser. Chim. 24, 1-48 (1941)

16. Meselson, M.. F.W. Stahl \& J. Vinograd: Equilibrium sedimentation of macromolecules in density gradients. Proc. Natl. Acad. Sci. U.S. 43, 581588 (1957)

17. Millero, F.J.: The molal volumes of electrolytes. Chem. Rev. 71, 147-176 (1971) 
18. OWen, B.B., R.C. Miller, C.E. Milner \& H.L. Cogan: The dielectric constant of water as a function of temperature and pressure. J. Phys. Chem. 65, 2065-2074 (1961)

19. Pedersen, T.G. \& J.B. IFFT: The buoyant titration of ovalbumin in four alkali halides. Hydration and ion binding. Carlsberg Res. Commun. 43, 65-76 (1978)

20. Picker,P., E. Tremblay, \& C. Jolicoeur: A highprecision digital readout flow densimeter for liquids. J. Solution Chem. 3, 377-384 (1973)

21. Pierotti, R.A.: Aqueous solutions of nonpolar gases. J. Phys. Chem. 69, 281-288 (1965)
22. Romankiw, L.A. \& I.Chou: Densities of aqueous $\mathrm{NaCl}, \mathrm{KCl}, \mathrm{MgCl}_{2}$ and $\mathrm{CaCl}_{2}$ binary solutions in the concentration range $0.5-6.1 \mathrm{~m}$ at $25,30,35$, 40 and $45{ }^{\circ} \mathrm{C}$. J. Chem. Eng. Data 28, 300-305 (1983)

23. STOKES, R.H. \& R.A. Robinson: Solvation equilibria in very concentrated electrolyte solutions. J. Solution Chem. 2, 173-184 (1973)

24. WEASt, R.C.: Handbook of Chemistry and Physics, 56th edition, B66-B160 (1976) 